\title{
Two heterocyst-specific DNA rearrangements of nif operons in Anabaena cylindrica and Nostoc sp. strain Mac
}

\author{
Claudio D. Carrasco and James W. Golden
}

Department of Biology, Texas A \& M University, College Station, TX 77843-3258, USA

\author{
Author for correspondence: James W. Golden. Tel: +1 409845 9823. Fax: +14098452891. \\ e-mail: jgolden@tamu.edu
}

\begin{abstract}
Two site-specific DNA rearrangements occur during heterocyst differentiation in the cyanobacterium Anabaena sp. strain PCC 7120: the deletion of an $11 \mathrm{~kb}$ element from within the nifD gene and the deletion of a $55 \mathrm{~kb}$ element from within the fdxN gene. Three Nostoc and six Anabaena strains were screened for the presence of the nifD and fdxN elements by Southern hybridization with Anabaena PCC 7120 DNA probes. Eight of the nine strains contained DNA sequences that were similar to the nifD element. Three strains, Nostoc sp. strain Mac, Anabaena cylindrica and Anabaena sp. strain M131, also showed significant similarity to portions of the $55 \mathrm{~kb}$ fdxN element. Anabaena sp. strain CA lacked both the nifD and forN elements. Southern analysis of vegetative cell and heterocyst DNA from A. cylindrica and a Fox ${ }^{+}$revertant of Nostoc Mac (isolate R2) showed rearrangement of the nifD and fdxN elements in heterocysts. We found no RFLPs between Anabaena M131 and Anabaena PCC 7120 suggesting that strain M131 is a Het' ${ }^{-}$derivative of strain PCC 7120.
\end{abstract}

Keywords : nitrogen fixation (nif) genes, cyanobacteria, DNA rearrangement, heterocyst, recombinase genes

\section{INTRODUCTION}

Many filamentous cyanobacteria form heterocysts, which are highly specialized, terminally differentiated cells that reduce atmospheric dinitrogen to ammonia (Haselkorn, 1978; Wolk, 1982). The fixed nitrogen is exported to neighbouring vegetative cells as glutamine and in return heterocysts are provided with photosynthate. Heterocysts are formed about every tenth cell along the filament of strains such as Anabaena sp. strain PCC 7120 and produce a semiregular one-dimensional pattern (Adams \& Carr, 1981; Wolk, 1989). Heterocyst formation is repressed by the presence of an external source of combined nitrogen, such as ammonia, or by the proximity of other heterocysts in the filament. Global changes in gene expression occur during heterocyst differentiation (Fleming \& Haselkorn, 1974; Lynn et al., 1986). For example, the genes responsible for nitrogen fixation are turned on while several genes necessary for carbon fixation and the oxygenevolving reactions of photosynthesis are turned off (Wolk, 1982).

Heterocyst differentiation in Anabaena PCC 7120 is accompanied by two developmentally regulated genome rearrangements that occur within the nifHDK and the nifB- $f d x N-n i f S-n i f U$ operons (Golden et al., 1985, 1988;
Golden, J. W. et al., 1987; Mulligan et al., 1988; Mulligan \& Haselkorn, 1989). The nifD rearrangement involves the deletion of an $11 \mathrm{~kb}$ element from within the $3^{\prime}$ end of the nifD gene. The nifD element is bordered by $11 \mathrm{bp}$ direct repeats and site-specific recombination between these sequences results in deletion of the $11 \mathrm{~kb}$ element from the chromosome (Golden et al., 1985). The nifD rearrangement results in the formation of the complete ORF for the nifD gene and allows for the expression of the nifHDK operon from a single promoter (Golden $e t$ al., 1991; Haselkorn et al., 1986). The $x i s A$ gene is located on the nifD element and encodes a site-specific recombinase that is required for excision of the element (Brusca et al., 1990; Golden \& Wiest, 1988; Lammers et al., 1986).

The $f d x N$ rearrangement is the result of the excision of a $55 \mathrm{~kb}$ element from within the $f d x N$ gene, which is part of the nifB-fdxN-nifS-nifU operon (Golden et al., 1988; Mulligan et al., 1988; Mulligan \& Haselkorn, 1989). A site-specific recombination between directly repeated DNA sequences also occurs, but these repeated sequences are different from those involved in the nifD rearrangement(Golden, J. W. et al., 1987). The deletion of the $55 \mathrm{~kb}$ element results in the formation of the $f d x N$ ORF and presumably allows for the expression of the downstream genes in the nifB- $f d x N-n i f S-n i f U$ operon by the 
nif $B$ promoter (Mulligan et al., 1988). The $x i s F$ gene is located on the $f d x N$ element and encodes a site-specific recombinase that is required for excision of the element (Carrasco et al., 1994). Excision of the $f d x N$ element can occur independently from excision of the nifD element (Carrasco et al., 1994; Golden et al., 1988; Golden \& Wiest, 1988).

Southern analysis and mapping of nitrogen fixation genes in several cyanobacterial strains with Anabaena PCC 7120 probes show that the nifHDK operon is not contiguous in most heterocystous strains (Apte \& Thomas, 1987; Franche \& Cohen-Bazire, 1985, 1987; Herrero \& Wolk, 1986; Kallas et al., 1983, 1985; Meeks et al., 1988). However, a branching heterocystous species, Fischerella sp. strain ATCC 27929 , contains a contiguous nifHDK organization (Saville et al., 1987). Anabaena torulosa contains sequences similar to the Anabaena PCC 7120 $x i s A$ gene (Apte $\&$ Thomas, 1987). Southern analysis of Nostoc sp. strain UCD 7801 and a cultured isolate from the symbiotic association with the water fern Azolla caroliniana showed hybridization to an $x i s A$ probe and evidence for rearrangement in samples that contained heterocysts (Meeks et al., 1988). These results indicate that a nifD element similar to that found in Anabaena PCC 7120 is present in many heterocystous strains and suggest that in these strains the element is excised from the nifHDK operon during heterocyst formation.

Rearrangement of the nifD element has been directly demonstrated in at least two strains other than Anabaena PCC 7120. Anabaena variabilis (ATCC 29413) contains an $11 \mathrm{~kb}$ element very similar to the Anabaena PCC 7120 nifD element (Brusca et al., 1989). DNA sequencing showed that the $A$. variabilis element is located at the same position in the $3^{\prime}$ region of the nifD gene and contains the same directly repeated sequences at the recombination sites as found in Anabaena PCC 7120 . The $A$. variabilis element contains an $x i s A$ gene that can functionally replace the Anabaena PCC $7120 x i s A$ gene and cause sitespecific recombination of a PCC 7120 substrate cloned in E. coli (Brusca et al., 1989).

Southern analysis of Nostoc sp. strain Mac showed the presence of a nifD element (Meeks et al., 1994). The common laboratory strain of Nostoc Mac is $\mathrm{Fox}^{-}$, incapable of aerobic nitrogen fixation. Analysis of spontaneous $\mathrm{Fox}^{+}$revertant clones identified one rare clone, isolate R1, that had lost the element in all cells (Meeks $e t$ al., 1994). DNA samples from other revertant clones, which still carry the nifD element, showed faint bands on Southern blots that were interpreted as representing excision of the element in heterocysts.

The Anabaena PCC 7120 DNA element found within the $f d x N$ gene has not been previously described in any other cyanobacterial strain. It has been shown that $A$. variabilis does not contain a $55 \mathrm{~kb}$ element in a position similar to that found in Anabaena PCC 7120 (Brusca et al., 1989; Herrero \& Wolk, 1986). Physical mapping of the chromosome near the nif genes showed that the $r b c L S$ operon in vegetative cells of $A$. variabilis is located approximately $10 \mathrm{~kb}$ away from the nifS gene, which is the same gene arrangement that is found in the Anabaena PCC 7120 heterocyst chromosome after excision of the $f d x N$ element.

We were interested in determining whether DNA elements similar to the $f d x N$ element found in Anabaena PCC 7120 were present in other cyanobacterial strains. We report in this paper the presence of an $f d x N$-like element in Nostoc Mac and Anabaena cylindrica and show that the element rearranges in heterocysts of both strains. A nifDlike rearrangement was also detected in $A$. cylindrica. As part of our study, we confirmed the observations of others that Anabaena sp. strain M131 is very closely related to Anabaena PCC 7120 (Alam et al., 1991; Bancroft \& Wolk, 1989; Cai, 1991).

\section{METHODS}

Cyanobacterial and bacterial strains and culture conditions. The cyanobacterial strains used in this study and their sources are listed in Table 1. Fresh water Anabaena and Nostoc strains were grown in $100 \mathrm{ml}$ liquid cultures of modified Allen \& Arnon medium diluted eightfold (AA/8) (Golden et al., 1991), and on plates of modified BG-11 medium solidified with $1.5 \%$ (w/v) agar (Brusca et al., 1990). Anabaena sp. strain CA was grown in ASP-2 medium (Bottomley et al., 1979). Filtersterilized sodium thiosulfate (1 $\mathrm{mM}$ final concentration) was added to the BG-11 agar medium just before pouring the plates. Large scale cultures of 1-81 were grown in modified AA/8 medium bubbled with $1 \%(\mathrm{v} / \mathrm{v}) \mathrm{CO}_{2}$ in air. Heterocyst differentiation was suppressed by the addition of ammonium sulfate $(2.5 \mathrm{mM})$. Cultures were synchronously induced to form heterocysts by transferring vegetative cells from $\mathrm{AA} / 8$ medium containing ammonium sulfate to $\mathrm{AA} / 8$ medium lacking a source of combined nitrogen. Light levels for the various growth conditions were as previously described (Golden $e t$ al., 1991).

Escherichia coli strains carrying plasmid clones were grown in Luria-Bertani (LB) liquid or agar-solidified medium with appropriate antibiotics according to standard procedures. Plasmids were maintained in E. coli strains HB101 or DH5 $\alpha$ and cosmids were maintained in strain ED8767 (Golden et al., 1988).

Heterocyst isolation. Heterocysts were isolated from induced filaments by adjusting the original induced culture to $0.25 \mathrm{M}$ sucrose, $50 \mathrm{mM}$ Tris $/ \mathrm{HCl}(\mathrm{pH} \mathrm{8.0)}, 10 \mathrm{mM}$ EDTA (pH 8.0) and $0.25 \mathrm{mg}$ lysozyme $\mathrm{ml}^{-1}$. The cells were stirred for $30 \mathrm{~min}$ at room temperature. They were collected by centrifugation and chilled on ice water. The cell pellet was resuspended in $500 \mathrm{ml}$ $50 \mathrm{mM}$ Tris/HCl (pH 8.0)-10 mM EDTA (pH 8.0)-0.25 M sucrose- $1 \%(\mathrm{w} / \mathrm{v})$ SDS and treated for $2 \mathrm{~min}$ with a Sonifier Cell Disruptor 350 (Branson Sonic Power Company) tapered microtip at an output control setting of 4 and $50 \%$ duty cycle. The heterocysts were collected by centrifugation at $5000 \mathrm{~g}$ for $3 \mathrm{~min}$ and the pellet was resuspended in $10 \mathrm{ml}$ cold TE buffer [10 mM Tris/HCl (pH 8.0), $1 \mathrm{mM}$ EDTA (pH 8.0)]. The heterocysts were washed twice with cold TE buffer by centrifugation at $2000 \mathrm{~g}$ for $5 \mathrm{~min}$ to remove remaining vegetative cells and debris. A modification of this procedure improves the quality of extracted RNA (Golden et al., 1991).

DNA manipulations. Rapid small-scale DNA preparations from Anabaena and Nostoc strains were made essentially as previously described (Golden et al., 1991). Larger-scale preparations of vegetative cell and heterocyst DNA were made as previously described (Golden et al., 1985; Golden, S. S. et al., 1987). 
Table 1. Occurrence of nifD and fdxN elements in Anabaena and Nostoc strains

The presence of the nifD and $f d x N$ elements and the $x i s A$ and $x i s F$ genes was determined by Southern hybridization; probes and hybridization conditions are described in Methods. +, Presence of distinct bands of at least moderate intensities; -, absence of distinct bands, although faint diffuse hybridization was sometimes observed; $+/-$, faint but distinct bands.

\begin{tabular}{|c|c|c|c|c|c|c|}
\hline Strain & Source & Heterocysts & nifD element & $x i s A$ gene & $f d x N$ element & $x i s F$ gene \\
\hline Anabaena PCC $7120^{*}$ & R. Haselkorn & + & + & + & + & + \\
\hline Anabaena M131 & C. P. Wolk & - & + & + & + & + \\
\hline A. cylindrica & C. P. Wolk & + & + & + & + & + \\
\hline Nostoc Mac & J. C. Meeks & - & + & + & + & + \\
\hline Nostoc Mac R1 & J. C. Meeks & + & - & - & + & + \\
\hline Nostoc Mac R2 & J. C. Meeks & + & + & + & + & + \\
\hline A. variabilis (ATCC 29413) & C. P. Wolk & + & + & + & - & - \\
\hline A. torulosa & J. Thomas & + & + & + & - & - \\
\hline A. azollae isolate A2 & J. C. Meeks & + & + & + & - & - \\
\hline Nostoc UCD 7801 & J. C. Meeks & + & + & + & - & $+1-$ \\
\hline Nostoc ATCC 29133 & J. C. Meeks & + & + & + & - & $+1-$ \\
\hline Anabaena CA & R. Haselkorn & + & - & - & - & - \\
\hline
\end{tabular}

* Reference strain from which the hybridization probes were obtained.

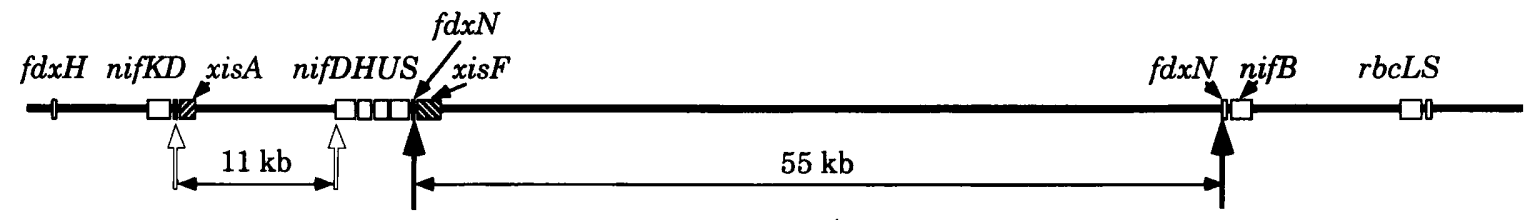

An207.6

An256

- An154.2

An155

nifD element

S2A12

T3D4

$5 \mathrm{~kb}$

T6C6

Fig. 1. Map of the Anabaena PCC 7120 vegetative cell chromosome and the cloned DNA fragments used as probes in this study. Vertical arrows indicate the recombination sites for the $11 \mathrm{~kb}$ nifD (white arrows) and $55 \mathrm{~kb}$ fdxN (black arrows) rearrangements. The DNA elements are excised from the genome by site-specific recombination during heterocyst differentiation. Genes involved in nitrogen fixation ( $n$ if and $f d x$ ) and carbon fixation ( $r b c$ ) are shown (open boxes). The xisA and xisf recombinase genes (hatched boxes) required for heterocyst-specific DNA rearrangement were used as probes. The fragments An207.6, An256, An154.2 and An155 span the recombination sites and were used as probes to detect excision of the elements. The nifD element probe was from a lambda clone, $\lambda$ HetL47.1-1.4, of the excised nifD element linearized at a Sau3Al site. The cosmid clones S2A12, T3D4 and T6C6 cover a $106 \mathrm{~kb}$ region of the chromosome that contains the nifD and $f d x N$ elements and flanking regions. Cosmid T3D4 contains sequences entirely within the $f d x N$ element.

Recombinant DNA techniques were performed by standard procedures (Ausubel et al., 1987; Maniatis et al., 1982). Restriction enzymes and other DNA modifying enzymes were obtained from various suppliers and used according to the manufacturers' recommendations. DNA was transferred from agarose gels to GeneScreen Plus (DuPont, NEN Research Products) with $0.4 \mathrm{M} \mathrm{NaOH}$ (Reed \& Mann, 1985) or $50 \mathrm{mM}$ $\mathrm{NaOH} / 1 \mathrm{M} \mathrm{NaCl}$. DNA probes were radiolabelled with a random primer kit (Bethesda Research Laboratories, Life Technologies or Boehringer Mannheim). Southern hybridizations were performed at moderate stringency because of the use of heterologous probes. Filters were hybridized in $5 \times$ SSPE (Maniatis et al., 1982) $/ 2 \%$ SDS at $55^{\circ} \mathrm{C}$ and washed in $5 \times \mathrm{SSPE} / 0.2 \% \mathrm{SDS}$ at $55^{\circ} \mathrm{C}$. DNA probes were stripped from filters by boiling for $20 \mathrm{~min}$ in $1 \%$ SDS- $10 \mathrm{mM}$ Tris $/ \mathrm{HCl}$ (pH 8.0)-1 mM EDTA ( $\mathrm{pH} \mathrm{8.0).}$ 
DNA probes. Most of the cloned DNA fragments used as probes in this study are shown in Fig. 1. The probes used to establish the presence or absence of the DNA elements (Table 1) were as follows: the nifD element probe was the entire element isolated as an EcoRI fragment from the clone $\lambda$ HetL47.1-1.4 (Fig. 1), which was constructed by cloning the excised nifD element linearized at a Sau3AI site into the lambda vector L47.1; the $x$ is $A$ gene probe was a $2 \cdot 0 \mathrm{~kb} B a m \mathrm{HI}-K p n I$ fragment from pAM264 (Brusca et al., 1990); the $f d x N$ element probe was the cosmid clone T3D4 (Fig. 1); and the $x i s F$ gene probe was a $2.5 \mathrm{~kb} \mathrm{NcoI}-X b a \mathrm{I}$ fragment from pAM896, which is equivalent to pAM1150 (Carrasco et al., 1994). Two additional probes were used in the analysis of Anabaena M131: the Anabaena PCC 7120 $g \ln A$ probe was a 430 bp HindIII-XbaI fragment from pCP106 (Ramasubramanian et al., 1994) and the $p s b A$ probe was from Synechococcus sp. strain PCC 7942 (Anacystis nidulans R2) (Golden et al., 1986).

Restriction map of Nostoc Mac. The restriction map of the Nostoc Mac nif region (Meeks et al., 1994) was confirmed and extended to include the $f d x N$ rearrangement. Southern analysis of single and double restriction enzyme digests with several different DNA probes (data not shown) was used to identify restriction fragment sizes near the $f d x N$ element recombination sites in vegetative cell and heterocyst DNA samples.

\section{RESULTS}

\section{Detection of nifD and $f d x N$ elements}

We surveyed several common laboratory strains of Anabaena and Nostoc for the presence of DNA sequences similar to the Anabaena PCC 7120 nif region, which contains the nifD and $f d x N$ elements. Initial Southern hybridization experiments used Anabaena PCC 7120 cosmid clones S2A12, T3D4 and T6C6 (Golden et al., 1988) as probes (Fig. 1). All tested strains showed hybridization with the S2A12 and T6C6 probes since they contain conserved genes involved in nitrogen and carbon fixation (data not shown). However, the T3D4 probe, which is internal to the $f d x N$ element, hybridized with only a subset of strains (Table 1). To further establish the presence or absence of sequences similar to the Anabaena PCC 7120 nifD and $f d x N$ elements, additional Southern experiments were done with probes for the $11 \mathrm{~kb}$ nifD element and the recombinase genes for the nifD and $f d x N$ elements, $x i s A$ (Lammers et al., 1986) and xisF (Carrasco et al., 1994), respectively (Table 1).

The Anabaena and Nostor strains could be placed into one of three groups: those with both elements, those with only the nifD element, and Anabaena CA, which lacked both elements. Anabaena M131, A. cylindrica and Nostoc Mac, like Anabaena PCC 7120, contain both elements and were further analysed (see below). Three Anabaena and two Nostoc strains contained the nifD element but lacked the $f d x N$ element. A. variabilis had been shown to contain the nifD element and an $x i s A$ gene (Brusca et al., 1989), and mapping data suggested that it lacked the $f d x N$ element (Herrero \& Wolk, 1986). Our hybridization experiments confirmed the absence of the $f d x N$ element and the $x i s F$ recombinase gene in the $A$. variabilis genome.

Anabaena CA, a marine heterocystous cyanobacterium (Bottomley et al., 1979), did not show hybridization with

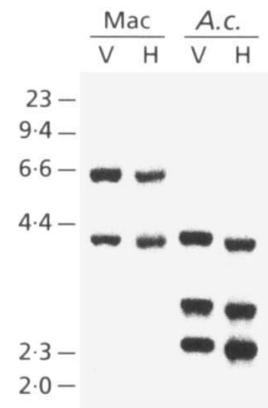

$0.56-$

Fig. 2. Nostoc Mac R2 (Mac) and A. cylindrica (A.C.) contain sequences that hybridize with the $f d x N$ element. A Southern blot of vegetative cell $(\mathrm{V})$ and heterocyst $(\mathrm{H})$ genomic DNA digested with EcoRI was hybridized at moderate stringency as described in Methods with Anabaena PCC 7120 cosmid clone T3D4. The positions of DNA size markers are shown on the left in kbp.

probes for either the nifD or $f d x N$ element, or with probes for the recombinase genes (Table 1).

Vegetative cell and heterocyst DNA was prepared for $A$. cylindrica and Nostoc Mac isolate R2 [a Fox ${ }^{+}$revertant containing the nifD element (Meeks et al., 1994)] to determine if in these strains the nifD and $f d x N$ elements are rearranged in heterocysts. Preliminary Southern analysis with S2A12 and T6C6 probes showed evidence for heterocyst-specific DNA rearrangements (data not shown) so these strains were chosen for further analysis.

\section{Nostoc Mac}

Southern analysis of Nostoc Mac vegetative cell DNA showed hybridization with probes for the nifD and $f d x N$ elements and their recombinase genes $x i s A$ and $x i s F$, respectively (Table 1 ). In agreement with a previous report, the nifD element has been lost from the Fox ${ }^{+}$ revertant isolate R1 (Meeks et al., 1994). Our further analysis of Nostoc Mac focused on the Fox ${ }^{+}$revertant isolate $\mathrm{R} 2$, which contains a nifD element (Meeks et al., 1994). The cosmid T3D4 probe, which contains approximately $35 \mathrm{~kb}$ of DNA internal to the $f d x N$ element, showed strong hybridization to two fragments in vegetative cell and heterocyst DNA (Fig. 2).

To determine if the $f d x N$-like element underwent rearrangement in Nostoc Mac R2 heterocysts, Southern analysis of vegetative cell and heterocyst DNA was performed. The Anabaena PCC 7120 fragments An154.2 and An155, which contain the borders of the $f d x N$ element, were used as probes against Nostoc Mac R2 DNA 


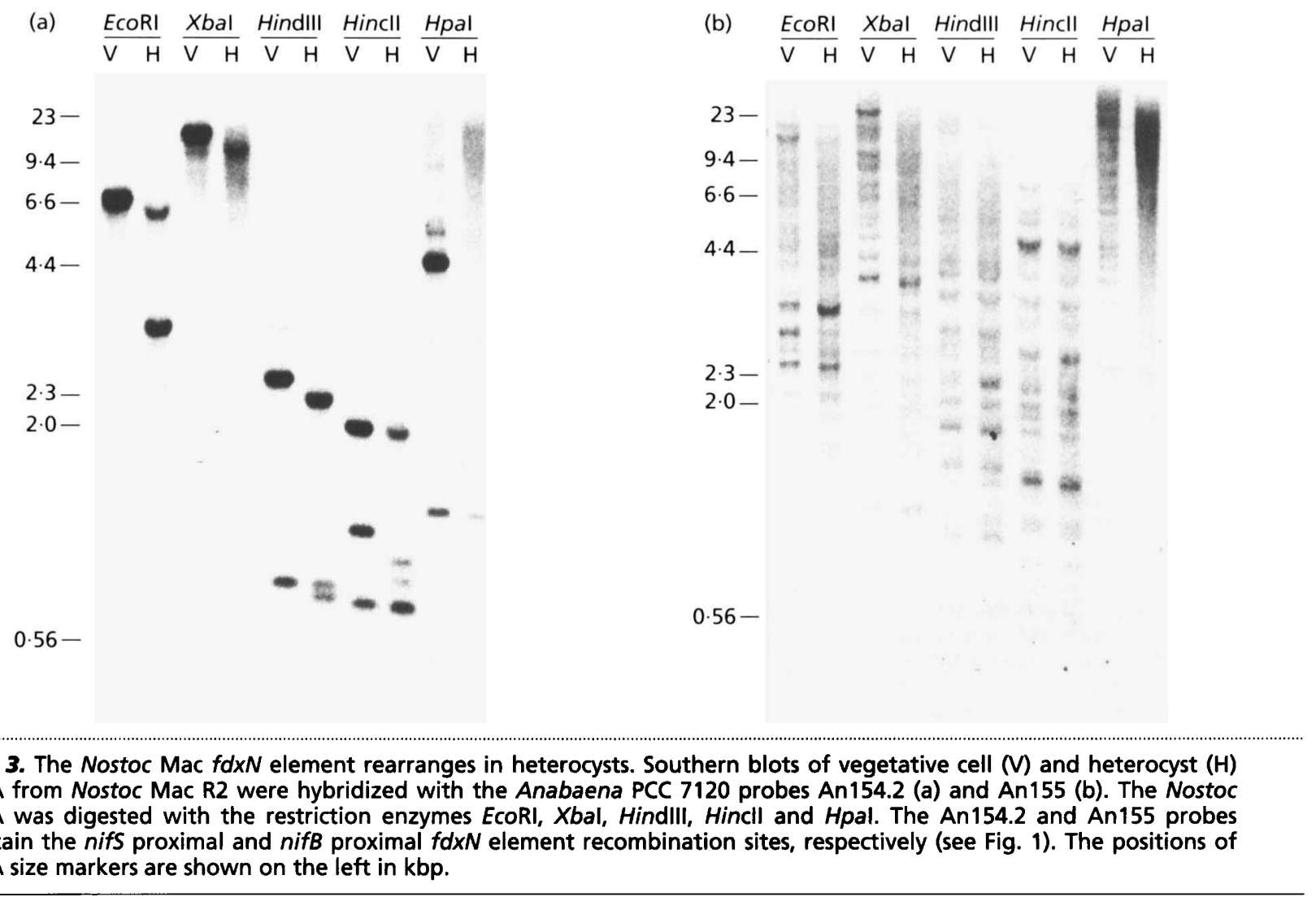

digested with several restriction enzymes (Fig. 3). The An154.2 probe showed clear evidence of DNA rearrangement; for example, in the EcoRI digest a $6.7 \mathrm{~kb}$ band in vegetative cell DNA was replaced by $6.2 \mathrm{~kb}$ and $3.1 \mathrm{~kb}$ bands in heterocyst DNA. The An155 probe, which is single copy in Anabaena PCC 7120 (Carrasco et al., 1994; Golden, J. W. et al., 1987), hybridized to multiple bands in Nostoc Mac (Fig. 3). Hybridization to the multi-copy element also occurred under more stringent $\left(65^{\circ} \mathrm{C}\right)$ washing conditions (data not shown). Despite the multiple bands, the An155 probe provided evidence for rearrangement of the $f d x N$ element by a reciprocal recombination event; for example, note the $3.1 \mathrm{~kb}$ EcoRI and $2.2 \mathrm{~kb}$ HindIII bands identified in heterocyst DNA by both probes.

We have confirmed and extended the map of the Nostoc Mac nif region (Meeks et al., 1994) to include the borders of the $f d x N$ element (Fig. 4). The size of the $f d x N$ element in Nostoc Mac is unknown. The approximate positions of the $x i s F$ and nifS genes are based on our hybridization results. The distal border of the $f d x N$ element in vegetative cells (Fig. 4b) is shown such that rearrangement results in excision of the element, however the orientation of this region is not known. The recombination site of the excised element is shown in Fig. 4(d).

\section{A. cylindrica}

Our initial Southern analysis of $A$. cylindrica vegetative cell DNA showed the presence of both the nifD and $f d x N$ elements (Table 1 ). The cosmid T3D4 probe showed strong hybridization to three EcoRI fragments in vegetative cell and heterocyst DNA (Fig. 2). Southern blots of $A$. cylindrica vegetative cell and heterocyst DNA were hybridized with DNA fragments containing the borders of the $f d x N$ and nifD elements to determine if the elements rearranged during development (Fig. 5). The results show clear evidence for rearrangement of both elements; however, our Southern analysis with heterologous probes has not allowed us to construct a restriction map or to establish that the rearrangements result from conservative recombination events.

For the $f d x N$ element, the An154.2 probe showed the appearance of $3.6 \mathrm{~kb}$ and $2.3 \mathrm{~kb}$ EcoRI fragments in the heterocyst chromosome (Fig. 5). Although the An155 probe seemed to show the appearance of the same two EcoRI fragments in heterocyst DNA, which would be indicative of a conservative recombination event, the data are difficult to interpret because this probe hybridized to multiple bands in $A$. cylindrica similar to the results found with Nostoc Mac (compare Figs 3 and 5). The data for $H$ indIII- and $X b a I$-digested DNA also show clear changes between vegetative cells and heterocysts indicating DNA rearrangement.

The probes for the nifD element, An207.6 and An256, showed that this element rearranges in $A$. cylindrica heterocysts (Fig. 5). The An207.6 probe showed striking changes in all three digested DNA samples. The An256 probe showed clear evidence of rearrangement only in 
(a)

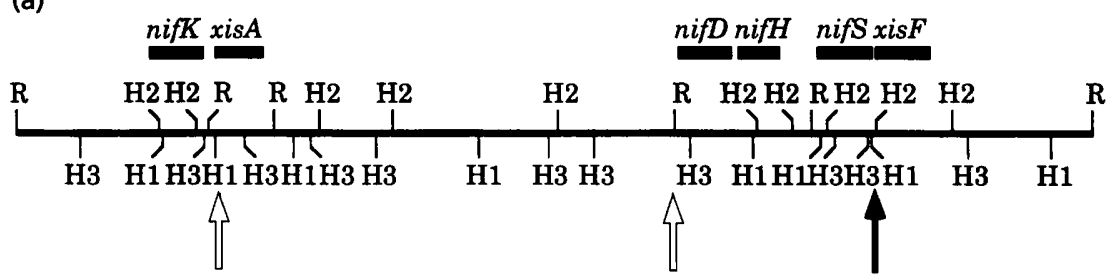

(b)

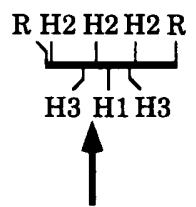

(c)

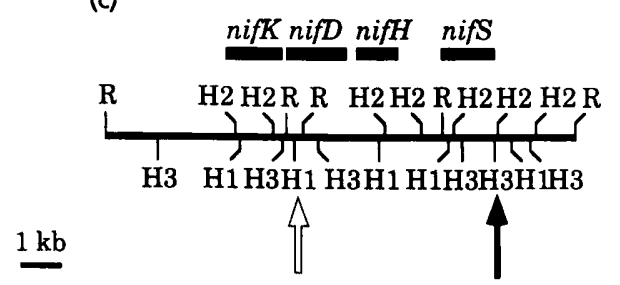

(d)

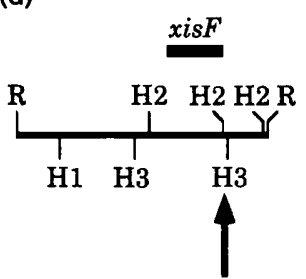

Fig. 4. Map of the Nostoc Mac regions involved in the nifD and $f d x N$ rearrangements. The restriction enzymes EcoRI (R), Hpal (H1), Hincll (H2) and HindIII (H3) were used to construct a restriction map of the chromosomal regions involved in the nifD and $f d x N$ rearrangements in vegetative cell $(a, b)$ and heterocyst $(c, d)$ DNA. The map shows the approximate positions of the nifK, xisA, nifD, nifH, nifS and xisf genes as determined by Southern analysis and comparison to Anabaena PCC 7120. Vertical arrows indicate the approximate positions of the recombination sites for the nifD (white arrows) and $f d x N$ (black arrows) rearrangements. (a) Vegetative cell chromosomal region containing the nifD element and the nifS proximal recombination site of the $f d x N$ element. (b) Region containing the nifS distal recombination site. (c) Heterocyst chromosome after rearrangement of the nifD and $f d x N$ elements. (d) Rearranged $f d x N$ element junction presumed to be on the excised $f d x N$ element. The excised nifD element is not shown.

(a) EcoRI HindIII Xbal uncut $\overline{\mathrm{VH}} \overline{\mathrm{VH}} \overline{\mathrm{VH}} \overline{\mathrm{VH}}$

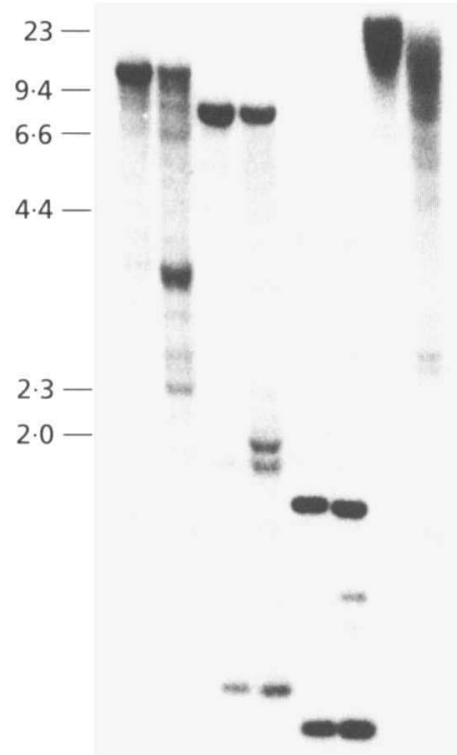

$0.56-$ (b) EcoRI HindIII Xbal uncut
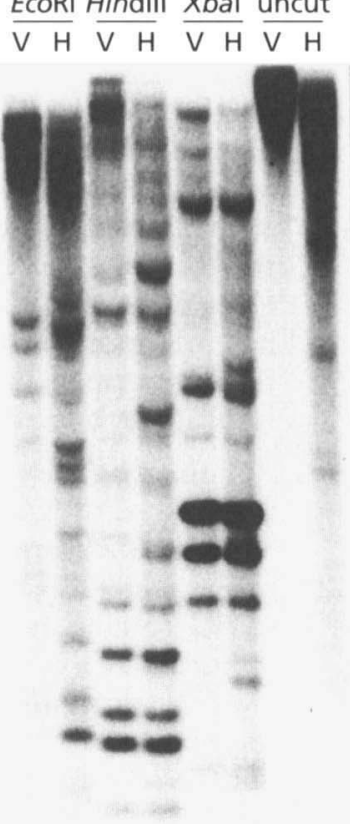

(c) EcoRI HindIII Xbal uncut $\frac{\mathrm{V} H}{\mathrm{VH}} \frac{\mathrm{V} \mathrm{H}}{\mathrm{VH}}$

d) EcoRI HindIII Xbal uncut $\overline{\mathrm{VH}} \overline{\mathrm{H}} \overline{\mathrm{VH}} \overline{\mathrm{VH}}$
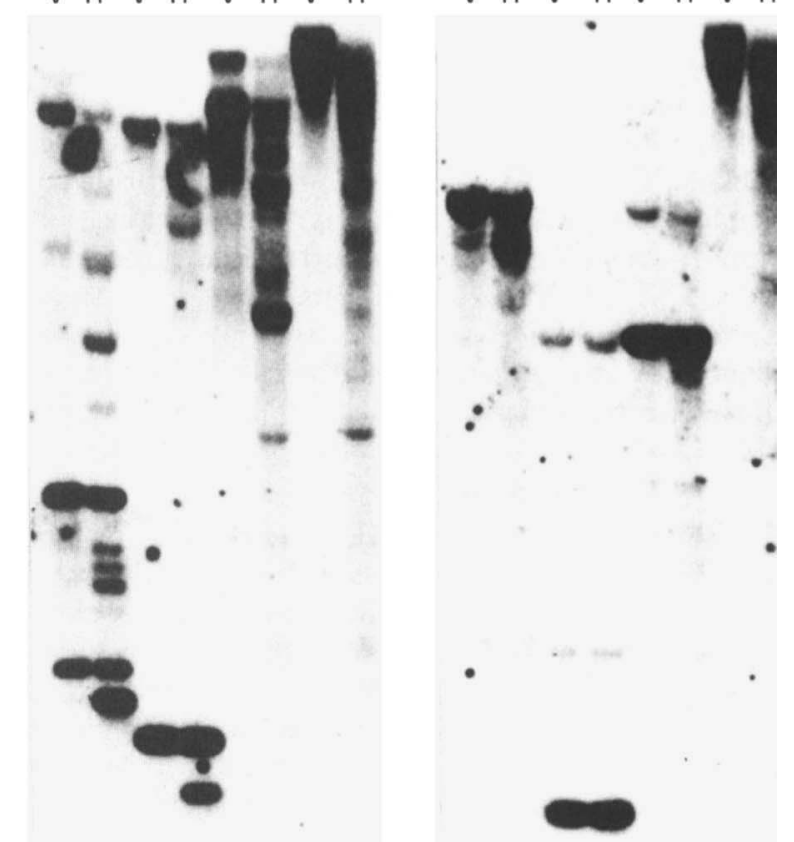

Fig. 5. A. cylindrica $f d x N$ and nifD elements rearrange in heterocysts. Southern blots of $A$. cylindrica vegetative cell (V) and heterocyst $(\mathrm{H})$ DNA either uncut or digested with the restriction enzymes EcoRI, HindllI or Xbal were probed with the Anabaena PCC 7120 fragments An154.2 (a) and An155 (b), which contain the fdxN element recombination sites, and An207.6 (c) and An256 (d), which contain the nifD element recombination sites (see Fig. 1). The positions of DNA size markers are shown on the left in kbp. 
EcoRI-digested DNA by the appearance of a $4.0 \mathrm{~kb}$ band in heterocyst DNA.

\section{Anabaena M131}

Anabaena M131 is a filamentous cyanobacterial strain that does not form heterocysts and cannot fix nitrogen aerobically. Our initial Southern analysis of Anabaena M131 (obtained from R. Haselkorn's laboratory) showed no differences between it and Anabaena PCC 7120 (data not shown). To confirm these results, we obtained an independent culture from C. P. Wolk's laboratory and performed RFLP analysis. Southern blots of Anabaena M131 and Anabaena PCC 7120 DNA samples were digested with the four restriction enzymes (EcoRI, $X b a \mathrm{I}$, HindIII and ClaI) and probed with three cosmid clones (S2A12, T3D4 and T6C6) that cover the nif and $r b c$ region (Fig. 1), and with probes for the $\operatorname{gln} A$ and $p s b A$ genes. Over 100 restriction fragments were detected with these probes. The analysis showed no RFLPs between Anabaena PCC 7120 and Anabaena M131, and showed that Anabaena M131 contains the nifD and $f d x N$ elements.

\section{DISCUSSION}

In Anabaena PCC $7120,11 \mathrm{~kb}$ and $55 \mathrm{~kb}$ DNA elements are found within the ORFs of the nifD and $f d x N$ genes, respectively. The elements excise from the chromosome during the late stages of heterocyst differentiation allowing the correct expression of the nifHDK and nifB- $f d x N-n i f S U$ operons. We have shown that two additional cyanobacterial strains, Nostoc Mac and $A$. cylindrica, contain both of these DNA elements and that the elements are rearranged in heterocysts. A third strain, Anabaena M131, also contained both DNA elements but RFLP analysis showed it to be very closely related to Anabaena PCC 7120. Our study identified three classes of strains: those mentioned above that contain both elements, those that contain only the nifD element, and Anabaena CA which lacks both elements.

Anabaena CA is distinct from the other strains examined in this study. It is a marine strain and shows differences in the regulation of heterocyst development and nitrogen fixation compared to fresh water strains (Bottomley et al., 1979). Recent analysis of its $r b c L-r b c S$ and $r c a$ genes showed significant differences from Anabaena PCC 7120 and $A$. variabilis (Li \& Tabita, 1994). It would not be too surprising if Anabaena CA does not contain either the nifD or $f d x N$ elements in its genome. However, we cannot exclude the possibility that the elements are present but have diverged to such an extent that they cannot be detected by our methods.

Evidence supporting the presence of a nifD element had been previously shown for some strains. A. torulosa has an $11 \mathrm{~kb}$ gap between the nifHD and nifK genes, and hybridizes with an $x i s A$ probe (Apte \& Thomas, 1987). Nostoc UCD 7801 and cultured isolates from $A$. caroliniana were shown to have a gap between nifHD and nifK, to hybridize with $x i s A$, and also to show evidence of rearrangement to form a contiguous nifHDK operon (Meeks et al., 1988). Nostoc ATCC 29133 was also reported to contain a nifD element (Meeks et al., 1994). In agreement with these earlier results, our hybridization experiments showed the presence of the nifD element and the $x i s A$ gene in each of these strains. Additionally, our results with the $f d x N$ element and $x i s F$ probes indicate that this element is absent from these strains.

All tested strains other than Anabaena CA contain the nifD element. Of these, three Anabaena and two Nostoc strains were found to be missing the $f d x N$ element. We know of no other characteristic that would group these five strains together. For example, Nostoc UCD 7801, Nostoc ATCC 29133 and Anabaena azollae isolate A2 are symbiotically competent (Meeks et al., 1988, 1994), but A. variabilis and $A$. torulosa are not known to be capable of symbiosis. Although it is not understood why these strains lack the $f d x N$ element, they clearly demonstrate that the $f d x N$ element is dispensable. The nifD element is widely distributed in Section IV (Rippka et al., 1979) nonbranching, heterocyst-forming species (Meeks et al., 1994). Our data suggests that the $f d x N$ element is not as widely distributed among Section IV strains.

Anabaena M131, A. cylindrica and Nostoc Mac contain both elements. The $f d x N$ element is therefore not unique to Anabaena PCC 7120. The $f d x N$ elements in Nostoc Mac and $A$. cylindrica showed only limited similarity to the Anabaena PCC $7120 \mathrm{fdx} N$ element when the cosmid T3D4 was used as a probe (Fig. 2) indicating significant divergence between the elements. The size of the $f d x N$ elements in Nostoc Mac and A. cylindrica was not determined. Although the $f d x N$ elements in Nostoc Mac and $A$. cylindrica have diverged significantly from the Anabaena PCC 7120 element, they show heterocystspecific rearrangement. This shows that the different elements have retained this aspect of their regulation.

It is thought that selective pressure, of unknown nature, accounts for the retention of the nifD element in the vegetative cell chromosome (Meeks et al., 1994). The $f d x N$ element has been retained in the strains discussed above throughout years of laboratory culturing, which also suggests that some type of selective pressure retains the element. However, the selection must be weak since the $f d x N$ element is absent from many strains and may only benefit the element itself. Perhaps the $f d x N$ element is similar to a lysogenic phage and has acquired developmental regulation as part of its life-cycle to keep it from harming its host under nitrogen-deficient conditions.

Anabaena M131 is very similar to Anabaena PCC 7120 ; our results showed no RFLPs between the two strains. Other investigators have previously noted a high degree of similarity between these strains by genome mapping experiments (Bancroft \& Wolk, 1989) and analysis of multicopy insertion sequences (Alam et al., 1991; Cai, 1991). Anabaena M131 does not form heterocysts or fix nitrogen aerobically suggesting that the strain has accumulated one or more spontaneous mutations during 
laboratory culturing. Anabaena PCC 7120 is known to contain active insertion sequences that could provide one mechanism for the proposed mutations (Cai, 1991).

\section{ACKNOWLEDGEMENTS}

We thank R. Haselkorn, J. C. Meeks, J. Thomas and C. P. Wolk for providing cyanobacterial strains. We thank J. C. Meeks for providing us with unpublished data. This work was supported by Public Health Service grant GM36890 from the NIH.

\section{REFERENCES}

Adams, D. G. \& Carr, N. G. (1981). The developmental biology of heterocyst and akinete formation in cyanobacteria. Crit $\mathrm{R} e v$ Microbiol 9, 45-100.

Alam, J., Vrba, J. M., Cai, Y., Martin, J. A., Weislo, L. J. \& Curtis, S.E. (1991). Characterization of the IS895 family of insertion sequences from the cyanobacterium Anabaena sp. strain PCC 7120. $J$ Bacteriol 173, 5778-5783.

Apte, S. K. \& Thomas, J. (1987). Nitrogen fixation genes (nifK, $D$, $H$ ) in the filamentous nonheterocystous cyanobacterium Plectonema boryanum do not rearrange. $J$ Genet 66, 101-110.

Ausubel, F. M., Brent, R., Kingston, R. E., Moore, D. D., Seidman, J. G., Smith, J. A. \& Struhl, K. (1987). Current Protocols in Molecular Biology. New York: Greene Publishing Associates \& WileyInterscience.

Bancroft, I. C. \& Wolk, C. P. (1989). Characterization of an insertion sequence (IS891) of novel structure from the cyanobacterium Anabaena sp. strain M-131. J Bacteriol 171, 5949-5954.

Bottomley, P. J., Grillo, J. F., Van Baalen, C. \& Tabita, F. R. (1979). Synthesis of nitrogenase and heterocysts by Anabaena sp. CA in the presence of high levels of ammonia. J Bacteriol 140, 938-943.

Brusca, J. S., Hale, M. A., Carrasco, C. D. \& Golden, J. W. (1989). Excision of an 11-kilobase-pair DNA element from within the nifD gene in Anabaena variabilis heterocysts. J Bacteriol 171, 4138-4145.

Brusca, J. S., Chastain, C. J. \& Golden, J. W. (1990). Expression of the Anabaena sp. strain PCC $7120 x i$ s $A$ gene from a heterologous promoter results in excision of the nifD element. $J$ Bacteriol 172, 3925-3931.

Cai, Y. (1991). Characterization of insertion sequence IS892 and related elements from the cyanobacterium Anabaena sp. strain PCC 7120. J Bacteriol 173, 5771-5777.

Carrasco, C. D., Ramaswamy, K. S., Ramasubramanian, T. S. \& Golden, J. W. (1994). Anabaena xisF gene encodes a developmentally regulated site-specific recombinase. Genes \& Dev 8, 74-83.

Fleming, H. \& Haselkorn, R. (1974). The program of protein synthesis during heterocyst differentiation in nitrogen-fixing bluegreen algae. Cell 3, 159-170.

Franche, C. \& Cohen-Bazire, G. (1985). The structural nif genes of four symbiotic Anabaena azollae show a highly conserved physical arrangement. Plant Sci 39, 125-133.

Franche, C. \& Cohen-Bazire, G. (1987). Evolutionary divergence in the nifK, $D, H$ gene region among nine symbiotic Anabaena azollae and between Anabaena azollae and some free-living heterocystous cyanobacteria. Symbiosis 3, 159-178.

Golden, J. W. \& Wiest, D. R. (1988). Genome rearrangement and nitrogen fixation in Anabaena blocked by inactivation of $x i s A$ gene. Science 242, 1421-1423.

Golden, J. W., Robinson, S. J. \& Haselkorn, R. (1985).
Rearrangement of nitrogen fixation genes during heterocyst differentiation in the cyanobacterium Anabaena. Nature 314, 419-423.

Golden, S. S., Brusslan, J. \& Haselkorn, R. (1986). Expression of a family of $p s b A$ genes encoding a photosystem II polypeptide in the cyanobacterium Anacystis nidulans R2. EMBO J 5, 2789-2798.

Golden, J. W., Mulligan, M. E. \& Haselkorn, R. (1987). Different recombination site specificity of two developmentally regulated genome rearrangements. Nature 327, 526-529.

Golden, S. S., Brusslan, J. \& Haselkorn, R. (1987). Genetic engineering of the cyanobacterial chromosome. Methods Enzymol 153, 215-231.

Golden, J. W., Carrasco, C. D., Mulligan, M. E., Schneider, G. J. \& Haselkorn, R. (1988). Deletion of a 55-kilobase-pair DNA element from the chromosome during heterocyst differentiation of Anabaena sp. strain PCC 7120. J Bacteriol 170, 5034-5041.

Golden, J. W., Whorff, L. L. \& Wiest, D. R. (1991). Independent regulation of nifHDK operon transcription and DNA rearrangement during heterocyst differentiation in the cyanobacterium Anabaena sp. strain PCC 7120. J Bacteriol 173, 7098-7105.

Haselkorn, R. (1978). Heterocysts. Annu Rev Plant Physiol 29, 319-344.

Haselkorn, R., Golden, J. W., Lammers, P. J. \& Mulligan, M. E. (1986). Developmental rearrangement of cyanobacterial nitrogenfixation genes. Trends Genet 2, 255-259.

Herrero, A. \& Wolk, C.P. (1986). Genetic mapping of the chromosome of the cyanobacterium, Anabaena variabilis. J Biol Chem 261, 7748-7754.

Kallas, T., Rebiere, M.-C., Rippka, R. \& Tandeau de Marsac, M. (1983). The structural nif genes of the cyanobacteria Gloeothece sp. and Calotbrix sp. share homology with those of Anabaena sp., but the Gloeothece genes have a different arrangement. J Bacteriol 155, 427-431.

Kallas, T., Coursin, T. \& Rippka, R. (1985). Different organization of nif genes in nonheterocystous and heterocystous cyanobacteria. Plant Mol Biol 5, 321-329.

Lammers, P. J., Golden, J. W. \& Haselkorn, R. (1986). Identification and sequence of a gene required for a developmentally regulated DNA excision in Anabaena. Cell 44, 905-911.

Li, L.-A. \& Tabita, F. R. (1994). Transcription control of ribulose bisphosphate carboxylase/oxygenase activase and adjacent genes in Anabaena species. J Bacteriol 176, 6697-6706.

Lynn, M. E., Bantle, J. A. \& Ownby, J. D. (1986). Estimation of gene expression in heterocysts of Anabaena variabilis by using DNA-RNA hybridization. J Bacteriol 167, 940-946.

Maniatis, T., Fritsch, E. F. \& Sambrook, J. (1982). Molecular Cloning: a Laboratory Manual. Cold Spring Harbor, NY: Cold Spring Harbor Laboratory.

Meeks, J. C., Joseph, C. M. \& Haselkorn, R. (1988). Organization of the nif genes in cyanobacteria in symbiotic association with Azolla and Anthoceros. Arch Microbiol 150, 61-71.

Meeks, J. C., Campbell, E. L. \& Bisen, P. S. (1994). Elements interrupting nitrogen fixation genes in cyanobacteria : presence and absence of a nifD element in clones of Nostoc sp. strain Mac. Microbiology 140, 3225-3232.

Mulligan, M. E. \& Haselkorn, R. (1989). Nitrogen-fixation (nif) genes of the cyanobacterium Anabaena sp. strain PCC 7120: the nifB-fdxN-nifS-nifU operon. J Biol Chem 264, 19200-19207.

Mulligan, M. E., Buikema, W. J. \& Haselkorn, R. (1988). Bacterialtype ferredoxin genes in the nitrogen fixation regions of the 
cyanobacterium Anabaena sp. strain PCC 7120 and Rbizobium meliloti. J Bacteriol 170, 4406-4410.

Ramasubramanian, T. S., Wei, T.-F. \& Golden, J. W. (1994). Two Anabaena sp. strain PCC 7120 DNA-binding factors interact with vegetative cell- and heterocyst-specific genes. $J$ Bacteriol 176, 1214-1223.

Reed, K. C. \& Mann, K. A. (1985). Rapid transfer of DNA from agarose gels to nylon membranes. Nucleic Acids Res 13, 7207-7221.

Rippka, R., Deruelles, J., Waterbury, J. B., Herdman, M. \& Stanier, R. Y. (1979). Generic assignments, strain histories and properties of pure cultures of cyanobacteria. J Gen Microbiol 111, 1-61.
Saville, B., Straus, N. \& Coleman, J. R. (1987). Contiguous organization of nitrogenase genes in a heterocystous cyanobacterium. Plant Pbysiol 85, 26-29.

Wolk, C. P. (1982). Heterocysts. In The Biology of Cyanobacteria, pp. 359-386. Edited by N. G. Carr \& B. A. Whitton. Berkeley: University of California Press.

Wolk, C. P. (1989). Alternative models for the development of the pattern of spaced heterocysts in Anabaena (Cyanopbyta). Plant Syst Evol 164, 27-31.

Received 1 May 1995; accepted 19 June 1995. 